\title{
Donor Site Location Is Critical for Proliferation, Stem Cell Capacity, and Osteogenic Differentiation of Adipose Mesenchymal Stem/Stromal Cells: Implications for Bone Tissue Engineering
}

\author{
Marie K. Reumann ${ }^{1}$, Caren Linnemann ${ }^{1}$, Romina H. Aspera-Werz ${ }^{1}$, Sigrid Arnold ${ }^{1}$, \\ Manuel Held ${ }^{1,2}$, Claudine Seeliger ${ }^{3,4}$, Andreas K. Nussler ${ }^{1, *}$ and Sabrina Ehnert ${ }^{1}$ \\ 1 Department of Trauma and Reconstructive Surgery, Siegfried Weller Research Institute, \\ Eberhard Karls University Tuebingen, BG Trauma Center Tuebingen, 72076 Tuebingen, Germany; \\ mreumann@bgu-tuebingen.de (M.K.R.); caren.linnemann@student.uni-tuebingen.de (C.L.); \\ rominaaspera@hotmail.com (R.H.A.-W.); sigrid-arnold@gmx.de (S.A.); mheld@bgu-tuebingen.de (M.H.); \\ sabrina.ehnert@gmail.com (S.E.) \\ 2 Department of Hand, Plastic, Reconstructive and Aesthetic Surgery, Eberhard Karls University Tuebingen, \\ BG Trauma Center Tuebingen, 72076 Tuebingen, Germany \\ 3 Else Kröner-Fresenius Center for Nutritional Medicine, Technical University of Munich, 85354 Freising, \\ Germany; claudine.seeliger@tum.de \\ 4 Experimental Trauma Surgery, Klinikum Rechts der Isar, Technical University of Munich, \\ 81675 Munich, Germany \\ * Correspondence: andreas.nuessler@med.uni-tuebingen.de; Tel.: +49-7071-606-1065
}

Received: 7 June 2018; Accepted: 22 June 2018; Published: 26 June 2018

\begin{abstract}
Human adipose mesenchymal stem/stromal cells (Ad-MSCs) have been proposed as a suitable option for bone tissue engineering. However, donor age, weight, and gender might affect the outcome. There is still a lack of knowledge of the effects the donor tissue site might have on Ad-MSCs function. Thus, this study investigated proliferation, stem cell, and osteogenic differentiation capacity of human Ad-MSCs obtained from subcutaneous fat tissue acquired from different locations (abdomen, hip, thigh, knee, and limb). Ad-MSCs from limb and knee showed strong proliferation despite the presence of osteogenic stimuli, resulting in limited osteogenic characteristics. The less proliferative Ad-MSCs from hip and thigh showed the highest alkaline phosphatase (AP) activity and matrix mineralization. Ad-MSCs from the abdomen showed good proliferation and osteogenic characteristics. Interestingly, the observed differences were not dependent on donor age, weight, or gender, but correlated with the expression of Sox2, Lin28A, Oct4 $\alpha$, and Nanog. Especially, low basal Sox 2 levels seemed to be pivotal for osteogenic differentiation. Our data clearly show that the donor tissue site affects the proliferation and osteogenic differentiation of Ad-MSCs significantly. Thus, for bone tissue engineering, the donor site of the adipose tissue from which the Ad-MSCs are derived should be adapted depending on the requirements, e.g., cell number and differentiation state.
\end{abstract}

Keywords: primary human adipose-derived mesenchymal stem/stromal cells (Ad-MSCs); proliferation; AP activity; matrix mineralization

\section{Introduction}

The regeneration of large bone defects after a trauma or tumor surgery is still a major issue in orthopedic surgery [1]. Treatment strategies require bone fixation in order to stabilize critical-size bone defects as well as to fill the structural gaps to allow bone bridging and, finally, healing [2]. Highly specialized surgical techniques have been deployed in order to reconstitute large bone defects, 
ranging from microvascular anastomosed autogenous bone grafting (fibula transfer flap) to Masquelet technique with Ilizarov external fixation and bone segmental transport. However, these methods require large amounts of bony tissue to fill the defects and provide mesenchymal stem/stromal cells (MSCs), which are essential to induce bone healing [3,4]. The most frequently used autologous bone grafting requires additional surgical intervention. However, this carries the risk of infection as well as morbidity at the donor site [5]. On the other hand, allogeneic bone tissue, which might serve as an alternative, can cause immunological reactions [6].

A possible alternative to bone tissue transplantation is alloplastic replacement with synthetic bone-filling materials. These materials, mainly used to fill the defect area, are then encapsulated in the connective tissue. Lacking osteoinductive capacity, these filling materials carry the risk of failing. Thus, tissue engineering with MSCs offers the advantage of providing large amounts of biologically active bone tissue to stimulate ossification and finally healing of critical-size bone defects [4]. Up to now, there are more than 350 clinical trials reported, which investigate the cell therapeutic potential of MSCs [7].

MSC are multipotent cells with high regenerative capacity and can be differentiated into various cell types, e.g., osteoblasts, chondrocytes, and adipocytes [8]. In addition to their potential of direct cell differentiation into the target tissue, MSCs trigger alternative mechanisms, such as secretion of growth factors, cytokines, or hormones. Also, MSCs interact with other cells by forming nanochannels or releasing extracellular vesicles and exosomes that contain proteins, mRNAs, or miRNAs. Thus, MSCs stimulate cell proliferation, reduce apoptosis, and, in some cases, even regulate the immune response [9].

Usually, for bone regeneration, MSCs are derived from bone marrow aspirates (B-MSCs). However, only limited amounts can be harvested to reduce the side effects, i.e., anemia [10]. A possible alternative is deriving MSCs from the adipose tissue (Ad-MSCs), which contains large amounts of stem cells [11] that can be obtained at lower risk (minimal invasive techniques) for the patient $[12,13]$. However, it is often critically discussed that Ad-MSCs possess only a limited osteogenic differentiation potential. Though transplanted undifferentiated Ad-MSCs and B-MSCs can be stimulated to bone tissue formation $[14,15]$, the newly formed bone tissue may show weaknesses in its mechanical properties: the mechanical stability (maximum load and elasticity) of scaffolds with Ad-MSCs was shown to be reduced compared to that of scaffolds with B-MSCs [16]. A reason for this, however, could be the support materials themselves, which are mostly flexible in order to transmit mechanical stimuli to the cells [17]. Former studies could show that donor age as well as cell culture duration adversely affect the osteogenic differentiation potential of Ad-MSCs via epigenetic changes [18-21]. The altered epigenetics affects the differentiation capacity by regulating the expression of transcription factors (Sox2, Lin28A, Oct4 $\alpha$, and Nanog) involved in the self-renewal of embryonic stem cells and the generation of induced pluripotent stem cells [21]. An increasing donor age is often associated with a decreased expression of Nanog, Oct4 $\alpha$, and Lin28A [21].

So far, little is known about the influence of the donor site on the osteogenic differentiation potential of Ad-MSCs. Therefore, the aim of this study was to compare the proliferation (increase in total protein content) and osteogenic differentiation potential (AP activity, matrix mineralization, expression of molecular markers (osteogenic transcription factors)) of primary human Ad-MSCs derived from adipose tissue obtained from different donor sites (abdomen, hip, thigh, knee, and limb). Furthermore, to assess the stem cell capacity of each donor site, we measured the expression levels of Sox2, Lin28A, Oct4 $\alpha$, and Nanog.

\section{Results}

\subsection{The Proliferation of Ad-MSCs Varies Depending on the Donor Site}

No significant differences were found in the number of Ad-MSCs obtained after collagenase digestion of fat tissues derived from different donor sites (abdomen, hip, thigh, knee, and limb). 
Cell expansion till passage three lasted for 3 to 4 weeks in all cells and was mainly dependent on the initial amount of cells. To compare the proliferation potential of Ad-MSCs derived from different donor sites, the cells were plated at a density of $10,000 \mathrm{cells} / \mathrm{cm}^{2}$ and cultured for 14 days in osteogenic differentiation medium. Immediately after plating, no significant difference in the amounts of cells could be detected, as measured by Sulforhodamine B (SRB) staining. Within the following 14 days, the amount of Ad-MSCs originally derived from the hip and thigh hardly increased $(10 \%$ and $6 \%$, respectively). However, significant increases in the cell amount of about $61 \%(p<0.01)$ and $65 \%$ $(p<0.001)$ were detected in the Ad-MSCs from the knee or abdomen, respectively. In addition, the Ad-MSCs from the limb showed the most extensive growth (Figure 1a) by increasing up to $81 \%$. As listed in Table 1, the average donor age as well as the gender distribution within the groups varied. In order to rule out variations based on donor age, the next step was to investigate the influence of donor age on proliferation. Comparing all donors-irrespective of fat tissue location-the proliferation potential of Ad-MSCs did not decrease significantly with the increase of the donor age (slope $=-0.0025 \pm 0.0069$, Figure 1b). Similarly, with increases in donor body mass index (BMI) (irrespective of fat tissue location), only a slight decrease (slope $=-0.0326 \pm 0.0169$, Figure 1c) in cell proliferation was observed. In addition, no significant difference in the proliferation potential of Ad-MSCs was observed with respect to the donor gender (Figure 1d).

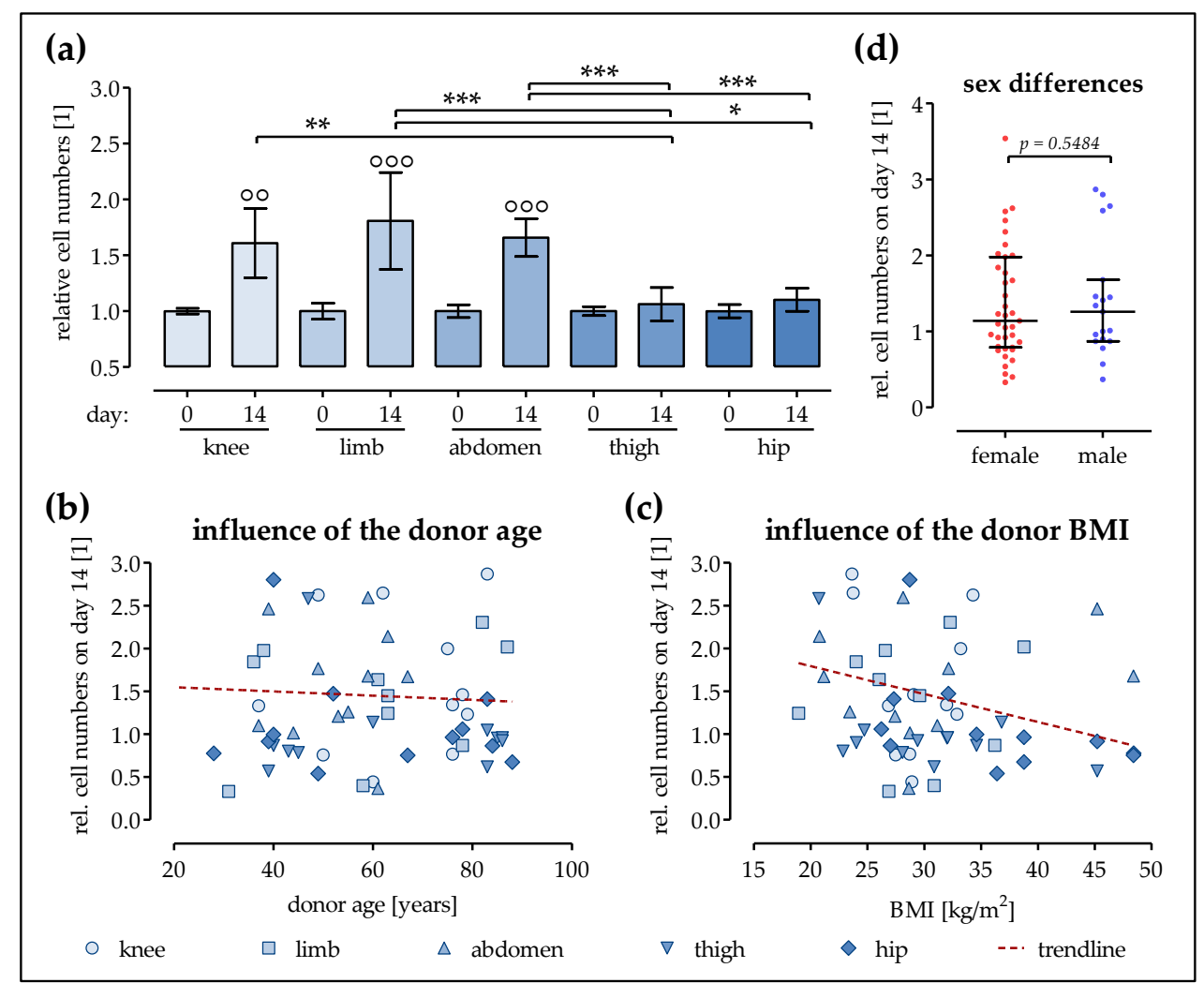

Figure 1. The proliferation of mesenchymal stem/stromal cells from adipose tissue (Ad-MSCs) varies depending on the donor site. Ad-MSCs derived from adipose tissue of the knee $(N=12), \operatorname{limb}(N=11)$, abdomen $(N=11)$, thigh $(N=12)$, and hip $(N=12)$ were osteogenically differentiated for 14 days. (a) To determine cell proliferation, the total protein content was determined by Sulforhodamine B (SRB) staining on days 0 and 14 of differentiation; (b) Relative cell numbers on day 14 of differentiation as a function of the donor age; (c) Relative cell numbers on day 14 of differentiation as a function of the donor body mass index (BMI); (d) Comparison of the relative cell numbers of differentiated (day 14) Ad-MSCs from male and female donors; ${ }^{\circ \circ} p<0.01$ and ${ }^{\circ 0 \circ} p<0.001$ when comparing day 0 with day 14 within each group; ${ }^{*} p<0.05,{ }^{* *} p<0.01$, and ${ }^{* * *} p<0.001$ as indicated. 


\subsection{Strongest Increase in AP Activity in Ad-MSCs of the Hip and Thigh}

In order to determine the osteogenic differentiation potential of Ad-MSCs derived from different donor sites, plated $\left(10,000\right.$ cells $\left./ \mathrm{cm}^{2}\right)$ cells were osteogenically differentiated for 14 days. Immediately after plating, the highest AP activity $\left(2.46 \pm 0.27 \mathrm{nmol} / \mathrm{h} / 10^{6}\right.$ cells $)$ was measured in Ad-MSCs derived from the thigh, followed by Ad-MSCs of the abdomen $\left(1.99 \pm 0.31 \mathrm{nmol} / \mathrm{h} / 10^{6}\right.$ cells $)$, extremities $\left(1.84 \pm 0.19 \mathrm{nmol} / \mathrm{h} / 10^{6}\right.$ cells $)$, and hip $\left(1.59 \pm 0.19 \mathrm{nmol} / \mathrm{h} / 10^{6}\right.$ cells). The lowest basal AP activity $\left(0.58 \pm 0.05 \mathrm{nmol} / \mathrm{h} / 10^{6}\right.$ cells $)$ was measured in the Ad-MSCs of the knee. After 14 days of differentiation, a significant increase in AP activity (1.2- to 1.7-fold) was found only in Ad-MSCs of the abdomen, hip, and thigh (Figure 2a). Similar to the SRB staining results, the AP activity did not decrease significantly with increases in donor age (slope $=0.0034 \pm 0.0096$, Figure $2 b$ ), when comparing all donors irrespective of the fat tissue location. Similarly, we observed only a slight increase in AP activity (slope $=0.0769 \pm 0.0218$, insignificant, Figure 2c) with increases in donor BMI (irrespective of fat tissue location). The sex of the donors also had no significant influence on AP activity (Figure 2d).

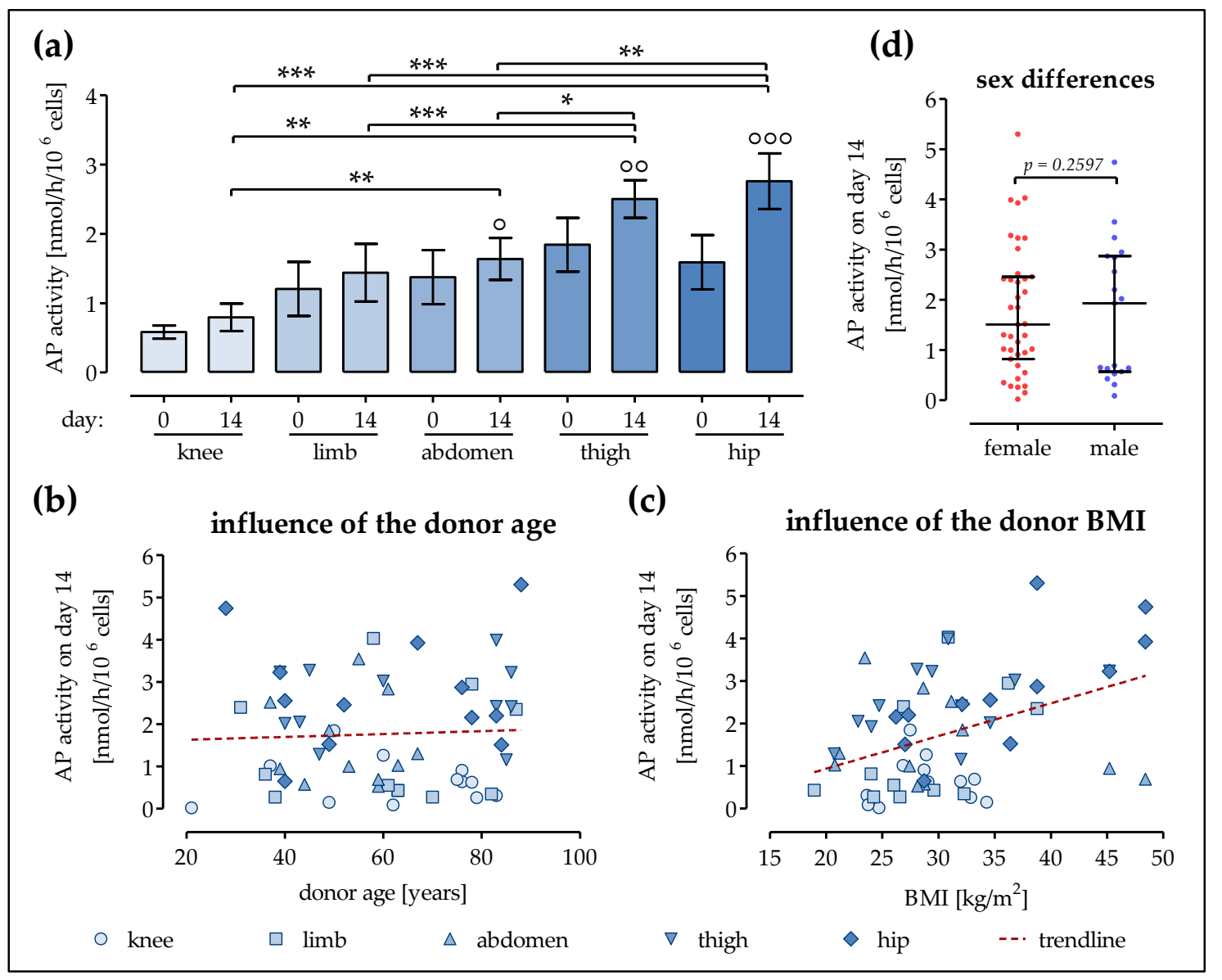

Figure 2. The alkaline phosphatase (AP) activity of Ad-MSCs varies depending on the donor site. Ad-MSCs derived from adipose tissue of the knee $(N=12), \operatorname{limb}(N=11)$, abdomen $(N=11)$, thigh $(N=12)$, and hip $(N=12)$ were osteogenically differentiated for 14 days. (a) AP activity was determined on days 0 and 14 of differentiation; (b) AP activity on day 14 of differentiation as a function of the donor age; (c) AP activity on day 14 of differentiation as a function of the donor BMI; (d) Comparison of the AP activity of differentiated (day 14) Ad-MSCs from male and female donors; ${ }^{\circ} p<0.05,{ }^{\circ \circ} p<0.01$, and ${ }^{\circ \circ \circ} p<0.001$ when comparing day 0 with day 14 within each group; * $p<0.05$, ** $p<0.01$, and ${ }^{* * *} p<0.001$ as indicated. 


\subsection{Strongest Matrix Mineralization in Ad-MSCs of the Hip and the Thigh}

The formation of mineralized matrix was determined by von Kossa and Alizarin Red staining for late markers for osteogenesis. As expected, there were no significant differences in matrix mineralization at day 0 (average $22.44 \pm 2.12 \mathrm{mg} / \mathrm{L}$ or Alizarin Red stain). After 14 days of osteogenic differentiation, tough, a significant increase in matrix mineralization was observed in all Ad-MSCs. The smallest increases were seen in Ad-MSCs of the knee (2.9-fold) and limb (18.9-fold). Significantly increased matrix mineralization was observed in Ad-MSCs from the abdomen (25.8-fold increase) and the thigh (42.2-fold increase). The strongest mineralized matrix was observed in Ad-MSCs of the hip (56.5-fold increase, Figure 3a,b). Similar to AP activity and proliferation potential, matrix mineralization did not decrease significantly with increases in donor age (slope $=-0.0046 \pm 0.0065$, Figure 3c) when comparing all donors (irrespective of fat tissue location). Similar to AP activity, we observed only a slight increase in matrix mineralization (slope $=0.0215 \pm 0.0160$, insignificant, Figure 3d) with increases in donor BMI (regardless of fat tissue location). There was also no significant difference in matrix mineralization in Ad-MSCs of female and male donors (Figure 3e).

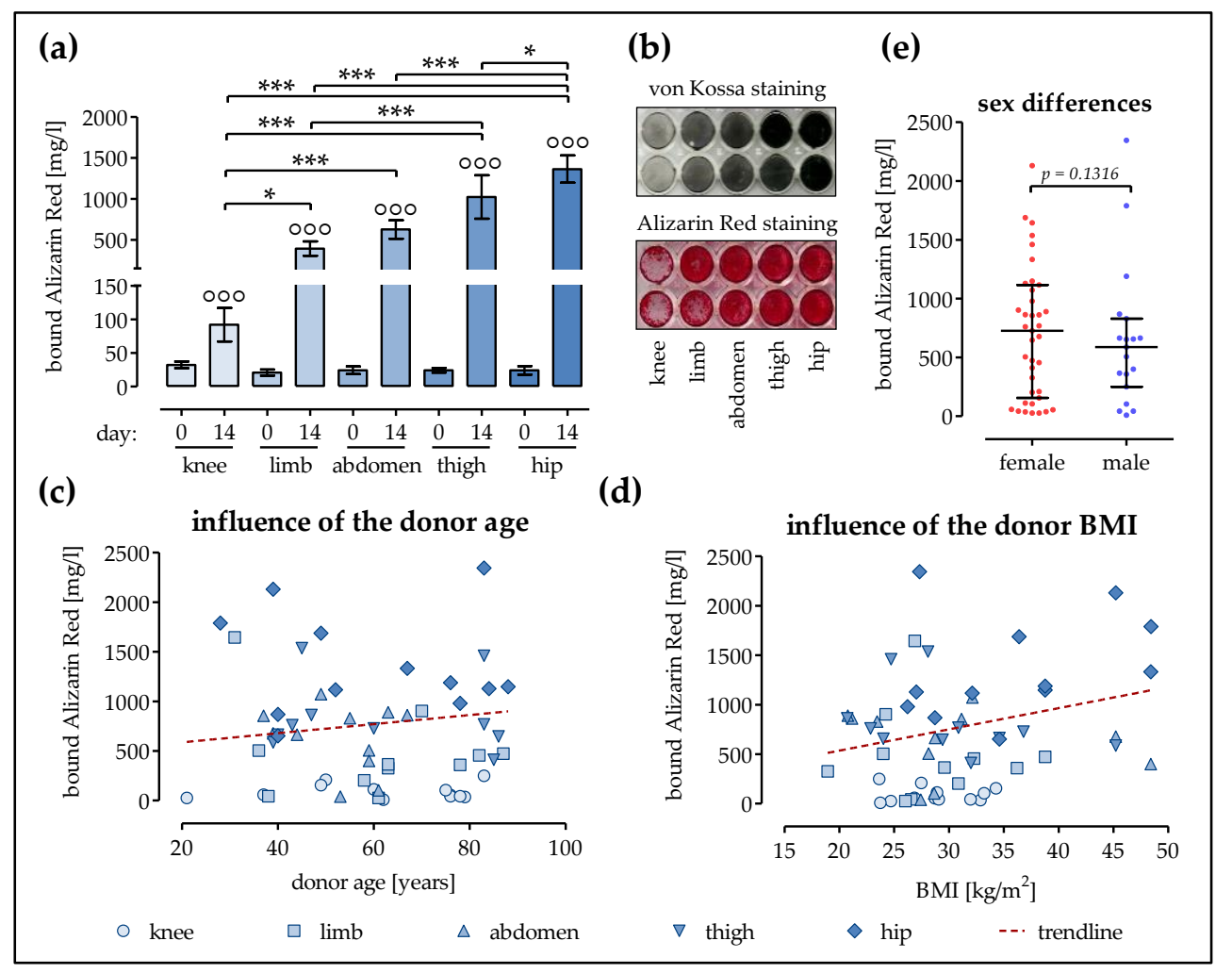

Figure 3. The formation of mineralized matrix by Ad-MSCs varies depending on the donor site. Ad-MSCs derived from adipose tissue of the knee $(N=12), \operatorname{limb}(N=11)$, abdomen $(N=11)$, thigh $(N=12)$, and hip $(N=12)$ were osteogenically differentiated for 14 days. (a) Matrix mineralization was quantified by Alizarin Red staining on days 0 and 14 of differentiation; (b) Representative scan of von Kossa- and Alizarin Red-stained Ad-MSCs from the different donor sites; (c) Mineralized matrix formed by differentiated (day 14) Ad-MSCs as a function of the donor age; (d) Mineralized matrix formed by differentiated (day 14) Ad-MSCs as a function of the donor BMI; (e) Comparison of the matrix mineralization of differentiated (day 14) Ad-MSCs from male and female donors; ${ }^{\circ \circ 0} p<0.001$ when comparing day 0 with day 14 within each group; ${ }^{*} p<0.05$ and ${ }^{* * *} p<0.001$ as indicated.

\subsection{The Expression of Runx2 and SP7 is the Highest in Ad-MSCs of the Abdomen, Thigh, and Hip}

The expression of the key osteogenic transcription factors Runx2 (early) and SP7 (late, encoding for osterix) was determined by semi-quantitative RT-PCR on day 14 of differentiation. Densitometric 
analysis (for a representative figure from the pooled samples see Figure 4c) revealed that, overall, the highest Runx2 levels were observed in Ad-MSCs of the thigh, followed by Ad-MSCs of the abdomen. Interestingly, Ad-MSCs of the hip showed slightly lower Runx2 expression levels. Ad-MSCs of the knee and the limb showed significantly lower Runx2 expression ( 0.6-fold, Figure 4a). Expression of SP7 in Ad-MSCs of the abdomen was approximately twice as high as in Ad-MSCs derived from the knee and limb. The highest SP7 levels were observed in Ad-MSCs of the thigh and hip (Figure 4b). These changes were confirmed at the protein level by Western blot, using pooled samples for each donor site (Figure $4 \mathrm{~d}$ ).

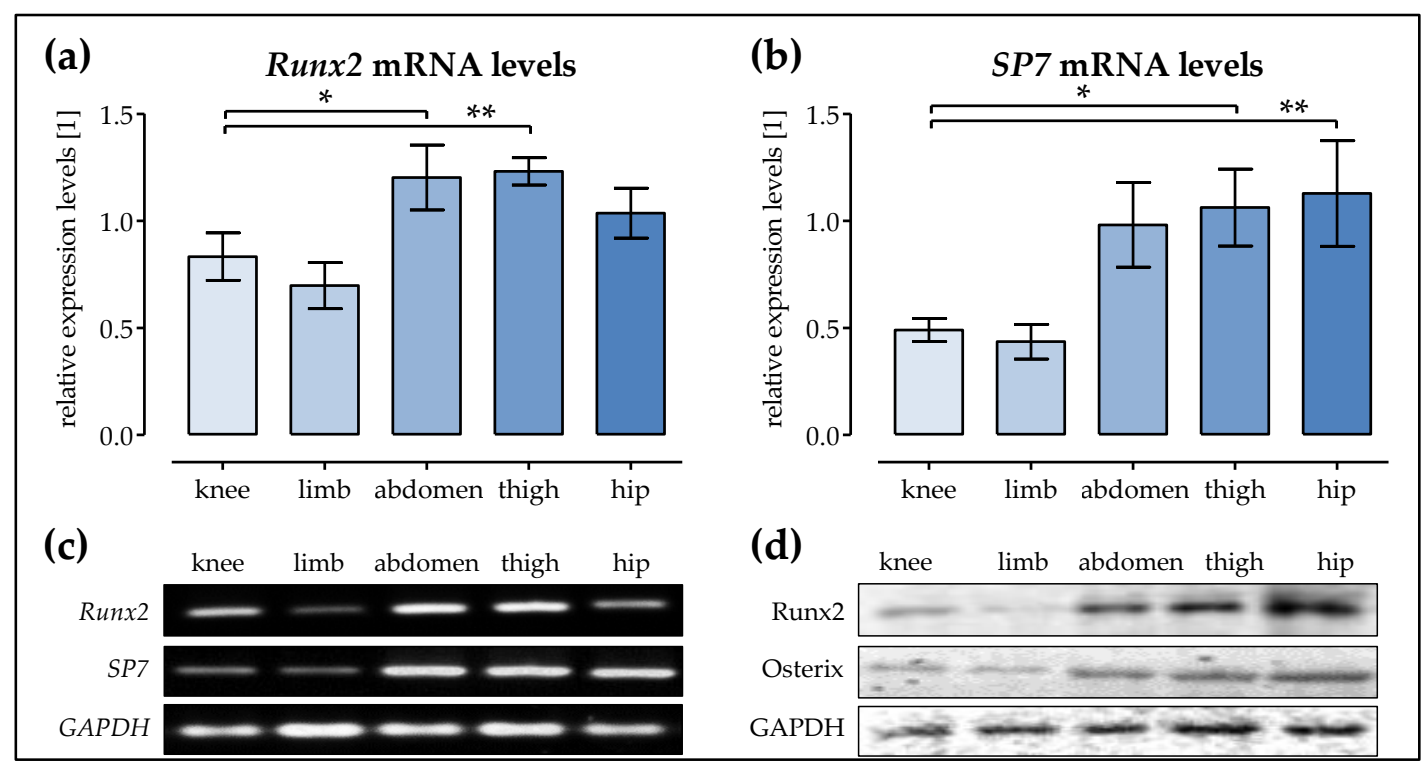

Figure 4. The expression of Runx2 and SP7 in Ad-MSCs varies depending on the donor site. Ad-MSCs derived from adipose tissue of the knee, limb, abdomen, thigh, and hip $(N=4$ each) were osteogenically differentiated for 14 days. The relative expression levels of (a) Runx2 and (b) SP7 were determined by semi-quantitative RT-PCR. The PCR products were loaded twice $(n=2)$ to minimize the loading errors. The signal intensities were quantified with the help of the ImageJ software; (c) Representative images for the RT-PCR products from the pooled samples; (d) Representative images for the Western blot signals obtained from the pooled samples; ${ }^{*} p<0.05$ and ${ }^{* *} p<0.01$ as indicated.

\subsection{The expression of the Stem ell Factors Oct4 $\alpha, \operatorname{Lin} 28 A$, and Nanog is the Highest in Ad-MSCs of the Hip and Thigh}

In order to possibly explain the observed changes in the osteogenic differentiation potential, we determined the expression of stem cell factors in the Ad-MSCs. The expression levels of Oct4 $\alpha$, Lin 28A, Nanog, and Sox 2 were determined by semi-quantitative RT-PCR before osteogenic differentiation (day 0). Densitometric analysis (for a representative figure from the pooled samples see Figure 5e) revealed the highest Oct4 $\alpha$ levels in Ad-MSCs of the thigh, followed by Ad-MSCs of the hip and abdomen. Ad-MSCs of the knee and limb showed significantly lower Oct $4 \alpha$ expression (Figure 5a). A similar pattern was observed for Lin $28 \mathrm{~A}$ expression. The highest expression levels of Lin28A were observed in Ad-MSCs of the thigh and the hip. Ad-MSCs from the abdomen showed slightly lower expression levels. The lowest expression levels for $\operatorname{Lin} 28 \mathrm{~A}$ were observed in Ad-MSCs from the limb and knee (Figure 5b). For Nanog expression levels, the effect was even more pronounced. The highest expression levels of Nanog were observed in Ad-MSCs of the thigh and the hip, followed by Ad-MSCs from the abdomen and limb. Ad-MSCs from the knee showed the lowest expression of Nanog (Figure 5b). Interestingly, the expression of Sox2 was the highest in Ad-MSCs from the knee. Ad-MSCs from the limb showed moderate Sox2 expression. Sox2 expression levels were further reduced in Ad-MSCs from the abdomen and barely detectable in Ad-MSCs from the thigh and hip (Figure 5d). 
These changes were confirmed at the protein level by Western blot, using pooled samples for each donor site (Figure 5f).

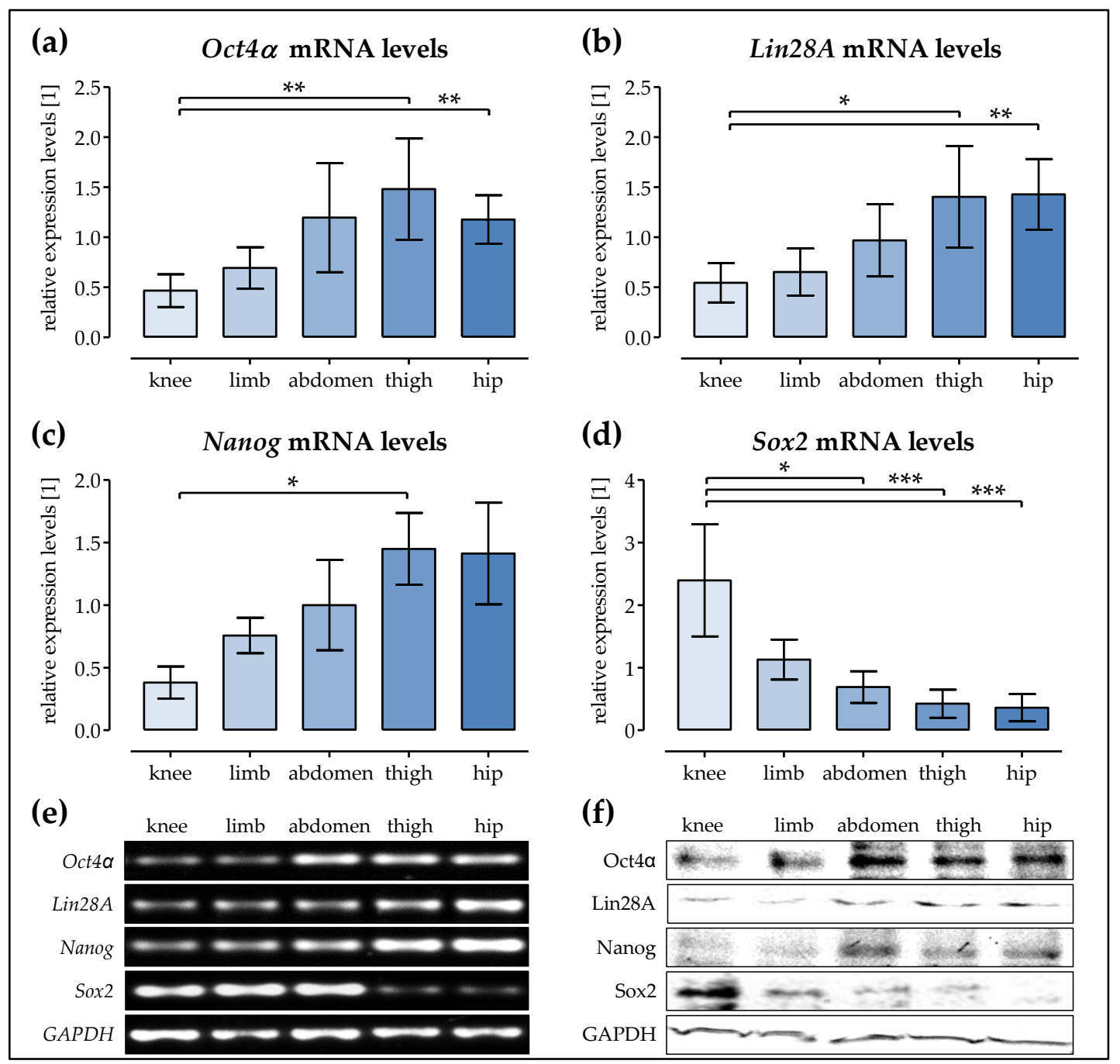

Figure 5. The expression of stem cell factors in Ad-MSCs varies depending on the donor site. The expression levels of the stem cell factors (a) Oct4 $\alpha$, (b) Lin28A, (c) Nanog, and (d) Sox2 were determined by semi-quantitative RT-PCR in Ad-MSCs derived from adipose tissue of the knee, limb, abdomen, thigh, and hip ( $N=4$ each). The PCR products were loaded twice $(n=2)$ to minimize the loading errors. The signal intensities were quantified with the help of the ImageJ software. (e) Representative images for the RT-PCR products from the pooled samples; (f) Representative images for the Western blot signals obtained from the pooled samples; ${ }^{*} p<0.05,{ }^{* *} p<0.01$, and ${ }^{* * *} p<0.001$ as indicated.

\section{Discussion}

The current standard of care for filling large bone defects is the transplantation of autologous or allogenic bone graft tissue. This provides the bone defect site with a sufficient number of potent MSCs to stimulate bone regeneration. Therefore, for tissue engineering, B-MSCs derived from bone marrow aspirates are commonly used. Animal models could show that undifferentiated B-MSCs have a stronger potential for bone formation than Ad-MSCs [14]. However, as harvesting bone marrow is strictly limited in quantity and represents a painful and sometimes risky procedure for the patient, adipose tissue as a possible resource for autologous MSCs should not be excluded [10,13]. Our data show that Ad-MSCs can be obtained from various subcutaneous adipose tissues. Its harvesting (even 
in larger amounts) bears only little risk for the patient compared to bone marrow grafting, as it can be obtained by minimally invasive surgical techniques [11].

However, the bone tissue newly formed by tissue engineering often lacks mechanical stability, especially when using undifferentiated MSCs as the biologically active component [17]. Prior in vitro cell conditioning, however, requires special approval. Thus, the used scaffolds need to support the undifferentiated cells to either allow direct osteogenesis or secrete paracrine factors. A modification of the in vitro differentiation protocol was able to show that the replacement of dexamethasone by cholecalciferol significantly improved the osteogenic differentiation of Ad-MSCs [12]. The supplementation of the culture medium with platelet lysate or platelet-rich plasma also improved the osteogenic differentiation of Ad-MSCs [14,22,23]. Also, the cultivation on three-dimensional scaffolds further improved the osteogenic properties of Ad-MSCs [24,25], amongst others, through the control of cell agglomeration [26]. Furthermore, co-cultivation with endothelial cells, vascular cells, or osteoblastic cells improved the osteogenic differentiation of Ad-MSCs [27-29]. Furthermore, the osteogenic differentiation of Ad-MSCs is regulated by oxygen saturation in the medium [30]. This shows the strong responsiveness of Ad-MSCs to the local environment. Thus, tissue engineering may take advantage of these factors.

However, the literature also shows that there are factors that cannot be influenced by autologous cell therapy. For example, a time-consuming in vitro cell expansion may reduce the osteogenic differentiation potential of the cells, which might be due to epigenetic changes in the cells $[18,19]$. Similar mechanisms were observed with respect to an increasing donor age [20,21]. In addition, the initial weight or BMI of the donor may have a decisive influence on the osteogenic differentiation of isolated MSCs, particularly in Ad-MSCs derived from subcutaneous adipose tissue [31]. Our data clearly show that the donor site of the subcutaneous adipose tissue used for cell isolation has a significant influence on the proliferation and osteogenic differentiation potential of the isolated Ad-MSCs. Ad-MSCs derived from limb, abdomen, and knee continue to proliferate despite the presence of differentiation stimuli. However, the development of osteogenic properties, such as AP activity and matrix mineralization, was more pronounced in less proliferative Ad-MSCs derived from hip and thigh.

In the Ad-MSCs with the strongest osteogenic characteristics, the expression of the key osteogenic transcription factors Runx2 and SP7 was increased compared to more proliferative Ad-MSCs. Interestingly, Runx2 levels were the highest in Ad-MSCs of the thigh and abdomen, and not the hip. It was reported that the early osteogenic transcription factor Run $x 2$ was reduced in favor of a faster induction of the late osteogenic transcription factor SP7 [32]. This is in line with our data, showing the highest SP7 expression levels in Ad-MSCs from the hip.

Within each group, a tendency towards an age-dependent decrease in osteogenic characteristics was visible, which is in line with our earlier observations [21]. However, comparing all samples with each other (regardless of the donor site) the observed effects were not age- or gender-specific. Furthermore, the donor BMI did not show a significant influence on the cells' proliferation and differentiation properties. This is supported by the fact that some of the donors provided adipose tissue from multiple donor sites, and the observed effects were pronounced in direct comparison, thus precluding donor variability.

In order to more closely investigate the differentiation capacity of the Ad-MSCs, the expression levels of the stem cell factors Oct4 $\alpha, \operatorname{Lin} 28 \mathrm{~A}, \mathrm{Nanog}$, and Sox2 was determined. Ad-MSCs derived from the hip, thigh, and abdomen, which all displayed good osteogenic characteristics, showed the highest expression levels of Oct $4 \alpha$ and Nanog, which are described as core transcription factors for the regulation and maintenance of pluripotency in embryonic stem cells $[33,34]$. Tsai and co-workers have shown that the osteogenic differentiation capacity of MSCs decreases with the increase of time in culture. This effect was shown to be regulated by the Oct4 $\alpha$ and Nanog expression [35]. In our earlier report, we have shown a similar trend dependent on the donor age [21]. However, this report focused 
on Ad-MSCs derived exclusively from the abdomen. In our present study, the effect of the donor site was more pronounced than the effect of the donor age.

Lin $28 \mathrm{~A}$ has been reported to promote cell proliferation in embryonic stem cells and breast tumor cells [36,37]. In our earlier work, its expression also decreased with the increase of the donor age, which positively correlated with the decreased proliferative capacity in these cells [21]. Interestingly, in this study, its expression was also the highest in Ad-MSCs derived from the hip and thigh, and not in the more proliferative Ad-MSCs from the knee, limb, or abdomen. As these Ad-MSCs were obtained from donors within a comparable age range, the effect of the donor site predominated.

Additionally, the basal expression levels of the stem cell factor Sox 2 were not comparable to the those of the other stem cell factors investigated. The highest basal expression of Sox2 was observed in Ad-MSCs from the knee. Sox 2 has been reported to regulate the proliferation and multipotency of stem cells in dependence of the cell density [38]. The over-expression of Sox 2 in c3h10t1/2 mouse embryonic stem cells effectively blocked their osteogenic differentiation [39]. This supports our observation that Ad-MSCs from the knee showed the least osteogenic characteristics. Ad-MSCs from the limb and the abdomen, showing strong proliferation despite the presence of osteogenic stimuli, showed moderate Sox2 expression levels. The lowest Sox 2 expression levels were observed in Ad-MSCs from the thigh and the hip, which showed the best osteogenic characteristics, suggesting that decreased Sox 2 expression levels may be pivotal for osteogenic differentiation. This is supported by the work of Park et al. showing that the depletion of Sox2 promotes osteogenic differentiation in mesenchymal stem cells from various tissues [40]. While this work proposes that Sox 2 might inhibit Wnt signaling by inducing the expression of its inhibitor dickkopf-1, the work of Marcellini et al. proposed a direct interaction of Sox 2 with its transcription factor $\beta$-catenin [41]. Furthermore, the work of Seo et al. showed that the over-expression of Sox 2 not only inhibited the osteogenic differentiation of B-MSCs, but also favored their adipogenic differentiation via PPAR $\gamma$ [42].

\section{Materials and Methods}

\subsection{Ethics Statement and Patient Information}

All experiments were carried out in accordance with the Declaration of Helsinki (1964). For this study, cells were derived from adipose tissue from patients treated in our level 1 trauma center. According to the corresponding ethical vote (385/2012BO2), tissue was only harvested after medical consultation and written patient consent. The performed orthopedic/trauma surgery did not undergo chances due to the harvesting procedure. This means that the patients had no additional risk for complications, which is in line with earlier reports [43]. Neither patients not able to give their consent nor patients with viral or bacterial infections were included in the study. Information on the donors is summarized in Table 1.

Table 1. Donor information.

\begin{tabular}{cccccc}
\hline & Knee & Limb & Abdomen & Thigh & Hip \\
\hline Number of donors & 12 & 11 & 11 & 12 & 12 \\
Sex (male/female) & $4 / 8$ & $2 / 9$ & $5 / 6$ & $3 / 9$ & $5 / 7$ \\
age (years) & $62.2 \pm 5.6$ & $60.6 \pm 5.7$ & $53.3 \pm 3.0$ & $63.4 \pm 6.3$ & $60.3 \pm 6.1$ \\
\hline
\end{tabular}

\subsection{Isolation, Expansion, and Differentiation of Primary Human Ad-MSCs}

Fat tissue (4-6 g per sample) was cut into mm-sized pieces using a scalpel and washed three to four times with phosphate buffered saline (PBS). For digestion, the pieces were incubated in $0.7 \%$ collagenase II solution (Biochrom, Berlin, Germany) for about $30 \mathrm{~min}$ at $37^{\circ} \mathrm{C}$. Collagenase digestion was stopped by adding culture medium (DMEM $4.5 \mathrm{~g} / \mathrm{L}$ glucose, $10 \% \mathrm{FCS}$ ). After centrifugation at $600 \times g$ for $10 \mathrm{~min}$, the Ad-MSC pellet was re-suspended in culture medium and expanded to passage $3\left(37{ }^{\circ} \mathrm{C}, 5 \% \mathrm{CO}_{2}\right)$. Flow cytometry revealed that in passage 3, Ad-MSCs were negative for CD14, 
CD45, and HLA-DR and positive for CD73, CD90, and CD105 (Figure 6), which is in line with our earlier reports [44]. Thus, in passage 3 , the cells $\left(10^{4}\right.$ cells $\left./ \mathrm{cm}^{2}\right)$ were osteogenically differentiated for 14 days. The osteogenic differentiation medium (DMEM $4.5 \mathrm{~g} / \mathrm{L}$ glucose, 1\% FCS, $200 \mu \mathrm{M}$ L-ascorbic acid 2-phosphate, $10 \mathrm{mM} \beta$-glycerol phosphate, $25 \mathrm{mM}$ HEPES, $1.5 \mathrm{mM} \mathrm{CaCl}_{2}, 5 \mu \mathrm{M}$ cholecalciferol) was replaced every $3-4$ days [12].

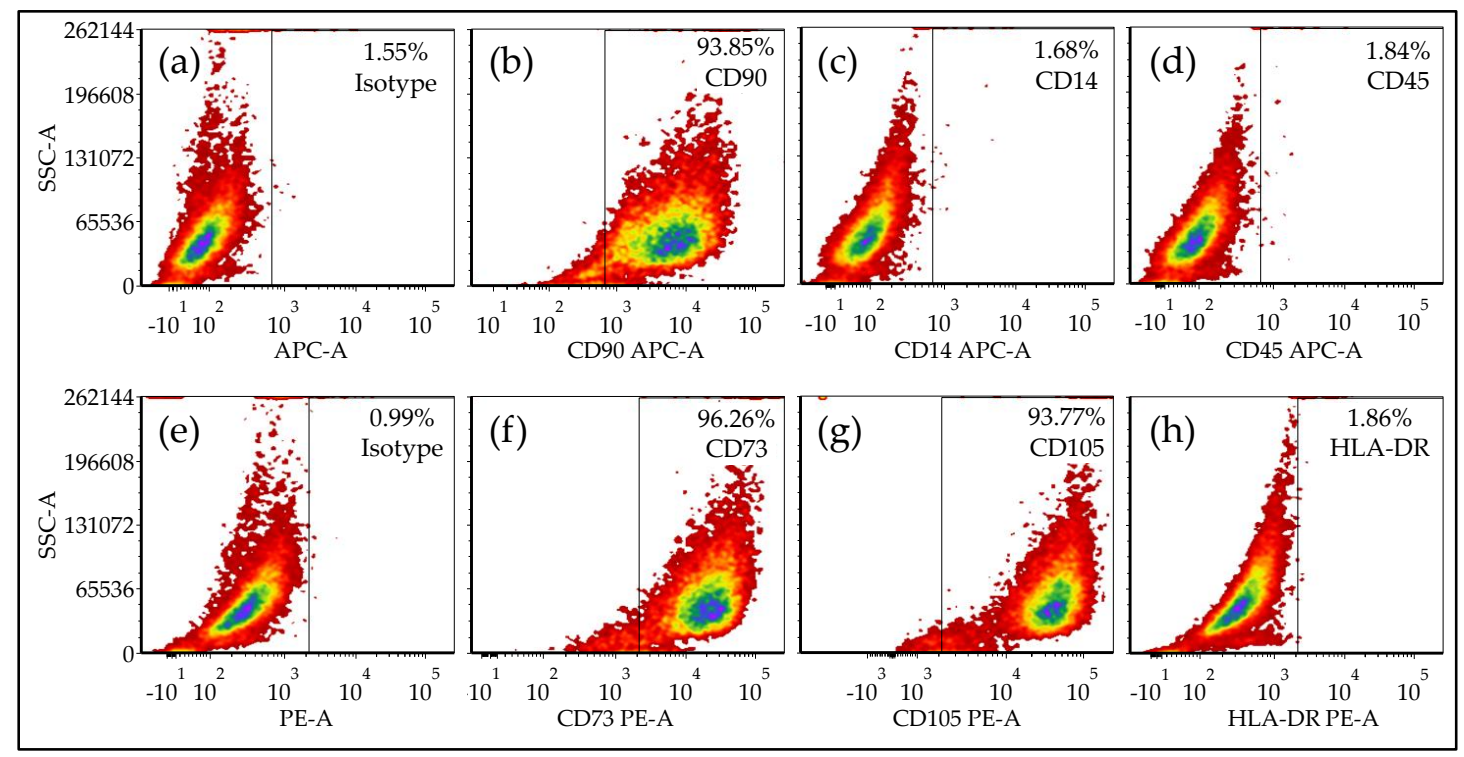

Figure 6. CD-marker expression in Ad-MSCs in passage 3. Ad-MSCs were stained for CD markers in passage 3. The analysis was done by flow cytometry as described [44] and is presented as scatter blot. Representative images for: (a) Isotype control for APC (allophycocyanin) secondary antibody. Ad-MSCs stained for (b) CD90-APC, (c) CD14-APC, and (d) CD45-APC. (e) Isotype control for PE (phycoerythrin) secondary antibody. Ad-MSCs stained for (f) CD73-PE, (g) CD105-PE, and (h) HLA-DR-PE.

\subsection{Sulforhodamine B (SRB) Staining}

To determine the number of cells by protein amount, the cells were fixed with ice-cold ethanol for $1 \mathrm{~h}$. The fixed cells were then stained with a $0.4 \%$ SRB solution (in 1\% acetic acid) for $20 \mathrm{~min}$. After washing five times with 1\% acetic acid, the remaining bound SRB was dissolved with $10 \mathrm{mM}$ unbuffered TRIS solution ( $\mathrm{pH} \sim 10.5$ ) and quantified photometrically at the wavelength of $565 \mathrm{~nm}$. The cell numbers were determined using a cell-specific standard curve, which was created during the course of the experiment [27].

\subsection{Alkaline Phosphatase (AP) Activity}

To determine AP activity, the cells were incubated at $37^{\circ} \mathrm{C}$ with the substrate solution $(1 \mathrm{mg} / \mathrm{mL}$ p-nitrophenyl phosphate, $50 \mathrm{mM}$ glycine, $1 \mathrm{mM} \mathrm{MgCl} 2,100 \mathrm{mM}$ TRIS, $\mathrm{pH}$ 10.5). The formed $p$-nitrophenol was measured photometrically at the wavelength of $405 \mathrm{~nm}$. The signal was normalized to the relative cell number as determined by SRB staining [45].

\subsection{Matrix Mineralization}

To analyze the mineralized matrix, the cells were fixed with ice-cold ethanol for $1 \mathrm{~h}$. The ethanol was then removed by washing three times with tap water. For von Kossa staining, the cells were covered with $3 \%$ silver nitrate solution for $30 \mathrm{~min}$. After washing three times with tap water, incubation with a developing solution (5\% Sodium carbonate, 10\% formaldehyde) and $5 \%$ sodium thiosulfate solution was performed for two minutes each. For Alizarin Red staining, the cells were covered for $30 \mathrm{~min}$ with a $0.5 \%$ Alizarin Red solution $(\mathrm{pH}=4.0)$. Unbound Alizarin Red was removed 
by washing with tap water. The dried plates were scanned. For quantification, the bound Alizarin Red was dissolved with a $10 \%$ cetylpyridinium chloride solution and quantified photometrically at a wavelength of $562 \mathrm{~nm}$ [45].

\subsection{Semi-Quantitative RT-PCR}

Total RNA was isolated using the Trifast reagent (Peqlab, Erlangen, Germany) as indicated by the manufacturer; cDNA sysnthesis was performed from $2 \mu \mathrm{g}$ total RNA using the First Strand cDNA Synthesis Kit from Fermentas (ThermoScientific, Karlsruhe, Germany). Gene expression changes were investigated by semi-quantitative RT-PCR using the KAPA2G Fast Ready Mix from Peqlab. PCR conditions are summarized in Table 2. PCR products were separated by agarose gel electrophoresis and visualized by ethidium bromide (geldoc, INTAS, Göttingen, Germany). Individual samples were run twice $(n=2)$ to reduce the variations caused by small loading differences. The signal intensities were quantified using the ImageJ software (NIH, version $1.49 \mathrm{~m})$ [31].

Table 2. PCR conditions.

\begin{tabular}{cccccc}
\hline Gene & $\begin{array}{c}\text { GeneBank ID } \\
\text { [NM] }\end{array}$ & Forward Primer & Reverse Primer & Ta [ $\left.{ }^{\circ} \mathbf{C}\right]$ & $\begin{array}{c}\text { Amplicon } \\
{[\mathbf{b} \mathbf{p}]}\end{array}$ \\
\hline Run $x 2$ & 001015051 & TGCCTAGGCGCATTTCAGGTGC & GGTGGTGGTGCATGGCGGAA & 58 & 359 \\
SP7 & 152860 & CCCAGGCAACACTCCTACTC & GGCTGGATTAAGGGGAGCAAA & 58 & 175 \\
Oct4a & 002701.4 & AGTGAGAGGCAACCTGGAGA & GCCTCAAAATCCTCTCGTTG & 59 & 180 \\
Lin $28 A$ & 024674.4 & CCGAACCCCATGCGCACGTT & TTTGCAGGTGGCTGCGCCAAG & 59 & 137 \\
Nanog & 024865.2 & AACTGGCCGAAGAATAGCAA & ACTGGATGTTCTGGGTCTGG & 59 & 175 \\
Sox2 & 003106.3 & CATGCACCGCTACGACG & CGGACTTGACCACCGAAC & 62 & 152 \\
GAPDH & 002046.4 & GTCAGTGGTGGACCTGACCT & AGGGGTCTACATGGCAACTG & 56 & 420 \\
\hline
\end{tabular}

Ta-annealing temperature.

\subsection{Western Blot}

The cells were lysed in freshly prepared ice-cold RIPA buffer. Amounts of $40 \mu \mathrm{g}$ of total protein (pooled samples, $N=5$ per donor site) were separated by SDS page and transferred to nitrocellulose membranes. The membranes were blocked with $5 \%$ BSA in TBS-T for $1 \mathrm{~h}$ followed by overnight incubation at $+4{ }^{\circ} \mathrm{C}$ with primary antibodies for RUNX2 (sc-10758, Santa Cruz Biotechnology, Heidelberg, Germany), Osterix (MAB7547/R\&D Systems), Oct $4 \alpha$, Lin28A, Nanog, and Sox2 (2840, 3695, 4903, and 3579, Cell Signaling Technology, Frankfurt am Main, Germany) diluted 1:1000 in TBS-T. The next day, the membranes were incubated with the corresponding peroxidase-labeled secondary antibodies (1:5000 in TBS-T, Santa Cruz Biotechnology) for $2 \mathrm{~h}$. GAPDH (G9545, Sigma-Aldrich, Munich, Germany) was used as a loading control. For signal development, the membranes were incubated for $1 \mathrm{~min}$ with ECL substrate solution. The chemiluminescent signals, detected by a CCD camera (INTAS), were quantified using the ImageJ software.

\subsection{Statistical Analysis}

Results are represented either as bar diagrams (mean $\pm 95 \%$ confidence interval) or as scatter diagrams. Each group consists of 11 or 12 donors $(N=11$ or 12$)$. All measurements were performed as quadruplicates $(n=4)$. The comparison of multiple groups was done using Kruskal-Wallis H-test, followed by Dunn's multiple comparison test. The comparison of two single groups was performed using the Mann-Whitney $U$-test (2-sided). Statistical analysis was performed with the help of the GraphPad Prism Software (Version 5, El Camino Real, CA, USA). A $p<0.05$ was considered as statistically significant.

\section{Conclusions}

In conclusion, we were able to show that Ad-MSCs can be efficiently differentiated to an osteogenic cell linage. However, the donor site of the adipose tissue is crucial, as it has a much greater impact on the proliferation and osteogenic differentiation potential of the primary human Ad-MSCs than age, 
BMI, and sex of the donors. The ability to acquire osteogenic characteristics went along with an elevated expression of $\operatorname{Oct} 4 \alpha, \operatorname{Lin} 28 \mathrm{~A}$, and Nanog, as well as a reduced expression of Sox2. The best osteogenic differentiation potential was shown by Ad-MSCs derived from hip adipose tissue, followed by thigh and abdominal adipose tissue. Ad-MSCs derived from the knee and the limb showed the strongest proliferation. However, a good proliferation potential together with a measurable increase in osteogenic characteristics were shown by Ad-MSCs derived from abdominal adipose tissue. Thus, depending on the requirements (cell amount and differentiation state), the donor site of adipose tissue could be adapted to obtain primary human Ad-MSCs.

Author Contributions: Conception, A.K.N. and S.E.; Methodology, C.S. and S.E.; Investigations, S.A., C.L., and R.H.A.-W.; Formal Analysis, S.E.; Resources, M.K.R. and M.H.; Writing-Original Draft Preparation, M.K.R. and S.E.; Writing-Review \& Editing, C.L., C.S., and A.K.N.; Visualization, R.H.A.-W. and S.E.; Supervision, A.K.N. and S.E.

Funding: M.K.R. received funding (own position) from the Clinician Scientist Program of the University of Tübingen. S.B. received a stipend from the IZKF Promotionskolleg of the University of Tübingen.

Acknowledgments: Part of this work was performed by S.A. for her medical doctoral thesis. We acknowledge support by Deutsche Forschungsgemeinschaft and Open Access Publishing Fund of University of Tübingen.

Conflicts of Interest: The authors declare no conflict of interest.

$\begin{array}{ll}\text { Abbreviations } \\ \text { Ad-MSCs } & \text { mesenchymal stem/stromal cells from adipose tissue } \\ \text { AP } & \text { alkaline phosphatase } \\ \text { BMI } & \text { body mass index } \\ \text { B-MSCs } & \text { mesenchymal stem/stromal cells from bone marrow } \\ \text { CD } & \text { cluster of differentiation } \\ \text { MSCs } & \text { mesenchymal stem/stromal cells } \\ \text { PBS } & \text { phosphate buffered saline } \\ \text { SRB } & \text { Sulforhodamine B } \\ \text { TBS-T } & \text { TRIS buffered saline containing tween-20 }\end{array}$

\section{References}

1. Smith, J.O.; Aarvold, A.; Tayton, E.R.; Dunlop, D.G.; Oreffo, R.O. Skeletal tissue regeneration: Current approaches, challenges, and novel reconstructive strategies for an aging population. Tissue Eng. Part B Rev. 2011, 17, 307-320. [CrossRef] [PubMed]

2. Kao, S.T.; Scott, D.D. A review of bone substitutes. Oral Maxillofac. Surg. Clin. N. Am. 2007, 19, 513-521. [CrossRef] [PubMed]

3. Granero-Molto, F.; Weis, J.A.; Miga, M.I.; Landis, B.; Myers, T.J.; O’Rear, L.; Longobardi, L.; Jansen, E.D.; Mortlock, D.P.; Spagnoli, A. Regenerative effects of transplanted mesenchymal stem cells in fracture healing. Stem Cells 2009, 27, 1887-1898. [CrossRef] [PubMed]

4. Watanabe, Y.; Harada, N.; Sato, K.; Abe, S.; Yamanaka, K.; Matushita, T. Stem cell therapy: Is there a future for reconstruction of large bone defects? Injury 2016, 47 (Suppl. 1), S47-S51. [CrossRef]

5. Scheerlinck, L.M.; Muradin, M.S.; van der Bilt, A.; Meijer, G.J.; Koole, R.; Van Cann, E.M. Donor site complications in bone grafting: Comparison of iliac crest, calvarial, and mandibular ramus bone. Int. J. Oral Maxillofac. Implants 2013, 28, 222-227. [CrossRef] [PubMed]

6. Shegarfi, H.; Reikeras, O. Review article: Bone transplantation and immune response. J. Orthop. Surg. 2009, 17, 206-211. [CrossRef] [PubMed]

7. Wei, X.; Yang, X.; Han, Z.P.; Qu, F.F.; Shao, L.; Shi, Y.F. Mesenchymal stem cells: A new trend for cell therapy. Acta Pharmacol. Sin. 2013, 34, 747-754. [CrossRef] [PubMed]

8. Dominici, M.; Le Blanc, K.; Mueller, I.; Slaper-Cortenbach, I.; Marini, F.; Krause, D.; Deans, R.; Keating, A.; Prockop, D.; Horwitz, E. Minimal criteria for defining multipotent mesenchymal stromal cells. The international society for cellular therapy position statement. Cytotherapy 2006, 8, 315-317. [CrossRef] [PubMed] 
9. Spees, J.L.; Lee, R.H.; Gregory, C.A. Mechanisms of mesenchymal stem/stromal cell function. Stem Cell Res. Ther. 2016, 7, 125. [CrossRef] [PubMed]

10. Bain, B.J. Bone marrow biopsy morbidity and mortality. Br. J. Haematol. 2003, 121, 949-951. [CrossRef] [PubMed]

11. Saler, M.; Caliogna, L.; Botta, L.; Benazzo, F.; Riva, F.; Gastaldi, G. Hasc and DFAT, multipotent stem cells for regenerative medicine: A comparison of their potential differentiation in vitro. Int. J. Mol. Sci. 2017, 18, 2699. [CrossRef] [PubMed]

12. Ehnert, S.; Häuser, J.; Kerler, I.; Schmitt, A.; Olderøy, M.; Freude, T.; Neumaier, M.; Egaña, T.; Schenck, T.; Stöckle, U.; et al. Mesenchymale stammzellen aus fettgewebe-Die bessere alternative zu knochenmarkszellen für das tissue engineering von knochen? Z. Regen. Med. 2011, 1, 3-8.

13. Schneider, S.; Unger, M.; van Griensven, M.; Balmayor, E.R. Adipose-derived mesenchymal stem cells from liposuction and resected fat are feasible sources for regenerative medicine. Eur. J. Med. Res. 2017, 22, 17. [CrossRef] [PubMed]

14. Niemeyer, P.; Fechner, K.; Milz, S.; Richter, W.; Suedkamp, N.P.; Mehlhorn, A.T.; Pearce, S.; Kasten, P. Comparison of mesenchymal stem cells from bone marrow and adipose tissue for bone regeneration in a critical size defect of the sheep tibia and the influence of platelet-rich plasma. Biomaterials 2010, 31, 3572-3579. [CrossRef] [PubMed]

15. Brennan, M.A.; Renaud, A.; Guilloton, F.; Mebarki, M.; Trichet, V.; Sensebe, L.; Deschaseaux, F.; Chevallier, N.; Layrolle, P. Inferior in vivo osteogenesis and superior angiogeneis of human adipose tissue: A comparison with bone marrow-derived stromal stem cells cultured in xeno-free conditions. Stem Cells Transl. Med. 2017, 6, 2160-2172. [CrossRef] [PubMed]

16. Tawonsawatruk, T.; West, C.C.; Murray, I.R.; Soo, C.; Peault, B.; Simpson, A.H. Adipose derived pericytes rescue fractures from a failure of healing-non-union. Sci. Rep. 2016, 6, 22779. [CrossRef] [PubMed]

17. Dawson, J.I.; Oreffo, R.O. Bridging the regeneration gap: Stem cells, biomaterials and clinical translation in bone tissue engineering. Arch. Biochem. Biophys. 2008, 473, 124-131. [CrossRef] [PubMed]

18. Liu, L.; Rando, T.A. Manifestations and mechanisms of stem cell aging. J. Cell Biol. 2011, 193, $257-266$. [CrossRef] [PubMed]

19. Li, Z.; Liu, C.; Xie, Z.; Song, P.; Zhao, R.C.; Guo, L.; Liu, Z.; Wu, Y. Epigenetic dysregulation in mesenchymal stem cell aging and spontaneous differentiation. PLoS ONE 2011, 6, e20526. [CrossRef] [PubMed]

20. Stolzing, A.; Jones, E.; McGonagle, D.; Scutt, A. Age-related changes in human bone marrow-derived mesenchymal stem cells: Consequences for cell therapies. Mech. Ageing Dev. 2008, 129, 163-173. [CrossRef] [PubMed]

21. Yan, X.; Ehnert, S.; Culmes, M.; Bachmann, A.; Seeliger, C.; Schyschka, L.; Wang, Z.; Rahmanian-Schwarz, A.; Stockle, U.; De Sousa, P.A.; et al. 5-azacytidine improves the osteogenic differentiation potential of aged human adipose-derived mesenchymal stem cells by DNA demethylation. PLoS ONE 2014, 9, e90846. [CrossRef] [PubMed]

22. Juhl, M.; Tratwal, J.; Follin, B.; Sondergaard, R.H.; Kirchhoff, M.; Ekblond, A.; Kastrup, J.; Haack-Sorensen, M. Comparison of clinical grade human platelet lysates for cultivation of mesenchymal stromal cells from bone marrow and adipose tissue. Scand. J. Clin. Lab. Investig. 2016, 76, 93-104. [CrossRef] [PubMed]

23. Tavakolinejad, S.; Khosravi, M.; Mashkani, B.; Ebrahimzadeh-Bideskan, A.; Sanjar-Mossavi, N.; Parizadeh, M.R.; Hamidi-Alamdari, D. The effect of human platelet-rich plasma on adipose-derived stem cell proliferation and osteogenic differentiation. Iran. Biomed. J. 2014, 18, 151-157. [PubMed]

24. Font Tellado, S.; Chiera, S.; Bonani, W.; Poh, P.S.P.; Migliaresi, C.; Motta, A.; Balmayor, E.R.; van Griensven, M. Heparin functionalization increases retention of TGF- $\beta 2$ and GDF5 on biphasic silk fibroin scaffolds for tendon/ligament-to-bone tissue engineering. Acta Biomater. 2018, 72, 150-166. [CrossRef] [PubMed]

25. Ruminski, S.; Ostrowska, B.; Jaroszewicz, J.; Skirecki, T.; Wlodarski, K.; Swieszkowski, W.; Lewandowska-Szumiel, M. Three-dimensional printed polycaprolactone-based scaffolds provide an advantageous environment for osteogenic differentiation of human adipose-derived stem cells. J. Tissue Eng. Regen. Med. 2018, 12, e473-e485. [CrossRef] [PubMed]

26. Furuhata, Y.; Yoshitomi, T.; Kikuchi, Y.; Sakao, M.; Yoshimoto, K. Osteogenic lineage commitment of adipose-derived stem cells is predetermined by three-dimensional cell accumulation on micropatterned surface. ACS Appl. Mater. Interfaces 2017, 9, 9339-9347. [CrossRef] [PubMed] 
27. Ehnert, S.; van Griensven, M.; Unger, M.; Scheffler, H.; Falldorf, K.; Fentz, A.K.; Seeliger, C.; Schroter, S.; Nussler, A.K.; Balmayor, E.R. Co-culture with human osteoblasts and exposure to extremely low frequency pulsed electromagnetic fields improve osteogenic differentiation of human adipose-derived mesenchymal stem cells. Int. J. Mol. Sci. 2018, 19, 994. [CrossRef] [PubMed]

28. Zhang, J.; Neoh, K.G.; Kang, E.T. Electrical stimulation of adipose-derived mesenchymal stem cells and endothelial cells co-cultured in a conductive scaffold for potential orthopaedic applications. J. Tissue Eng. Regen. Med. 2018, 12, 878-889. [CrossRef] [PubMed]

29. Choi, J.W.; Shin, S.; Lee, C.Y.; Lee, J.; Seo, H.H.; Lim, S.; Lee, S.; Kim, I.K.; Lee, H.B.; Kim, S.W.; et al. Rapid induction of osteogenic markers in mesenchymal stem cells by adipose-derived stromal vascular fraction cells. Cell. Physiol. Biochem. 2017, 44, 53-65. [CrossRef] [PubMed]

30. Fotia, C.; Massa, A.; Boriani, F.; Baldini, N.; Granchi, D. Prolonged exposure to hypoxic milieu improves the osteogenic potential of adipose derived stem cells. J. Cell. Biochem. 2015, 116, 1442-1453. [CrossRef] [PubMed]

31. Ehnert, S.; Fentz, A.K.; Schreiner, A.; Birk, J.; Wilbrand, B.; Ziegler, P.; Reumann, M.K.; Wang, H.; Falldorf, K.; Nussler, A.K. Extremely low frequency pulsed electromagnetic fields cause antioxidative defense mechanisms in human osteoblasts via induction of $\bullet \mathrm{O}_{2}{ }^{-}$and $\mathrm{H}_{2} \mathrm{O}_{2}$. Sci. Rep. 2017, 7, 14544. [CrossRef] [PubMed]

32. Yoshida, C.A.; Komori, H.; Maruyama, Z.; Miyazaki, T.; Kawasaki, K.; Furuichi, T.; Fukuyama, R.; Mori, M.; Yamana, K.; Nakamura, K.; et al. SP7 inhibits osteoblast differentiation at a late stage in mice. PLoS ONE 2012, 7, e32364. [CrossRef] [PubMed]

33. Niwa, H.; Miyazaki, J.; Smith, A.G. Quantitative expression of oct-3/4 defines differentiation, dedifferentiation or self-renewal of es cells. Nat. Genet. 2000, 24, 372-376. [CrossRef] [PubMed]

34. Masui, S.; Nakatake, Y.; Toyooka, Y.; Shimosato, D.; Yagi, R.; Takahashi, K.; Okochi, H.; Okuda, A.; Matoba, R.; Sharov, A.A.; et al. Pluripotency governed by Sox2 via regulation of Oct3/4 expression in mouse embryonic stem cells. Nat. Cell Biol. 2007, 9, 625-635. [CrossRef] [PubMed]

35. Tsai, C.C.; Su, P.F.; Huang, Y.F.; Yew, T.L.; Hung, S.C. Oct4 and nanog directly regulate dnmt1 to maintain self-renewal and undifferentiated state in mesenchymal stem cells. Mol. Cell 2012, 47, 169-182. [CrossRef] [PubMed]

36. Feng, C.; Neumeister, V.; Ma, W.; Xu, J.; Lu, L.; Bordeaux, J.; Maihle, N.J.; Rimm, D.L.; Huang, Y. Lin28 regulates HER2 and promotes malignancy through multiple mechanisms. Cell Cycle 2012, 11, 2486-2494. [CrossRef] [PubMed]

37. Xu, B.; Zhang, K.; Huang, Y. Lin28 modulates cell growth and associates with a subset of cell cycle regulator mrnas in mouse embryonic stem cells. RNA 2009, 15, 357-361. [CrossRef] [PubMed]

38. Yoon, D.S.; Kim, Y.H.; Jung, H.S.; Paik, S.; Lee, J.W. Importance of Sox 2 in maintenance of cell proliferation and multipotency of mesenchymal stem cells in low-density culture. Cell Prolif. 2011, 44, 428-440. [CrossRef] [PubMed]

39. Ding, D.; Xu, H.; Liang, Q.; Xu, L.; Zhao, Y.; Wang, Y. Over-expression of Sox2 in c3h10t1/2 cells inhibits osteoblast differentiation through wnt and mapk signalling pathways. Int. Orthop. 2012, 36, 1087-1094. [CrossRef] [PubMed]

40. Park, S.B.; Seo, K.W.; So, A.Y.; Seo, M.S.; Yu, K.R.; Kang, S.K.; Kang, K.S. Sox2 has a crucial role in the lineage determination and proliferation of mesenchymal stem cells through Dickkopf-1 and c-MYC. Cell Death Differ. 2012, 19, 534-545. [CrossRef] [PubMed]

41. Marcellini, S.; Henriquez, J.P.; Bertin, A. Control of osteogenesis by the canonical Wnt and BMP pathways in vivo: Cooperation and antagonism between the canonical wnt and bmp pathways as cells differentiate from osteochondroprogenitors to osteoblasts and osteocytes. Bioessays 2012, 34, 953-962. [CrossRef] [PubMed]

42. Seo, E.; Basu-Roy, U.; Gunaratne, P.H.; Coarfa, C.; Lim, D.S.; Basilico, C.; Mansukhani, A. Sox2 regulates YAP1 to maintain stemness and determine cell fate in the osteo-adipo lineage. Cell Rep. 2013, 3, 2075-2087. [CrossRef] [PubMed]

43. Asti, A.; Gastaldi, G.; Dorati, R.; Saino, E.; Conti, B.; Visai, L.; Benazzo, F. Stem cells grown in osteogenic medium on PLGA, PLGA/HA, and titanium scaffolds for surgical applications. Bioinorg. Chem. Appl. 2010, 2010, 831031. [CrossRef] [PubMed] 
44. Seeliger, C.; Culmes, M.; Schyschka, L.; Yan, X.; Damm, G.; Wang, Z.; Kleeff, J.; Thasler, W.E.; Hengstler, J.; Stockle, U.; et al. Decrease of global methylation improves significantly hepatic differentiation of ad-mscs: Possible future application for urea detoxification. Cell Transplant. 2013, 22, 119-131. [CrossRef] [PubMed]

45. Ehnert, S.; Falldorf, K.; Fentz, A.-K.; Ziegler, P.; Schröter, S.; Freude, T.; Ochs, B.G.; Stacke, C.; Ronniger, M.; Sachtleben, J.; et al. Primary human osteoblasts with reduced alkaline phosphatase and matrix mineralization baseline capacity are responsive to extremely low frequency pulsed electromagnetic field exposure-Clinical implication possible. Bone Rep. 2015, 3, 48-56. [CrossRef] [PubMed]

(C) 2018 by the authors. Licensee MDPI, Basel, Switzerland. This article is an open access article distributed under the terms and conditions of the Creative Commons Attribution (CC BY) license (http:/ / creativecommons.org/licenses/by/4.0/). 